\title{
Fetal phenytoin exposure, hypoplastic nails, and jitteriness
}

\author{
S W D'Souza, I G Robertson, D Donnai, G Mawer
}

\begin{abstract}
In a prospective study infants born to mothers with epilepsy ( $n=61$ ) were found to have an unexpectedly high incidence of congenital anomalies (26/61, 43\%) and neonatal conditions $(26 / 61,43 \%)$ compared with controls $(0 / 62$, and $6 / 62,10 \%$, respectively). There were two neonatal deaths in the study group but none among the controls. Hypoplasia of the finger or toenails was a common congenital anomaly in those infants whose mothers had received phenytoin alone or in combination with other anticonvulsant drugs ( 11 of 40 , $28 \%$ ). The mean serum phenytoin concentration was higher among mothers of infants with hypoplastic nails than among those with normal nails. Jitteriness was a common neonatal condition affecting infants of epileptic mothers ( 11 of $61,18 \%$ ) but not controls. The mean cord serum phenytoin concentrations were similar among jittery and nonjittery infants. At follow up (after excluding one infant with Down's syndrome from the study group) the infants seemed to have developed normally, though one had serious learning difficulties at school. We suggest that hypoplasia of the nails is related to high maternal serum concentrations of phenytoin, and though $18 \%$ of infants born to epileptic mothers were jittery compared with no control infants this may not be the result of withdrawal of the drug in all cases.
\end{abstract}

An excess of relatively minor congenital anomalies has been reported among children of epileptic mothers ${ }^{1-4}$ as well as serious defects such as cardiovascular malformations, cleft lip or palate, and inguinal hernia. ${ }^{25} 6$ The minor congenital anomalies include hypoplastic nails, distal phalangeal hypoplasia, epicanthic folds, hypertelorism, long philtrum, abnormal ears, and low hairline. ${ }^{4} \mathrm{~A}$ combination of some of these features associated with microcephaly, growth deficiency, and mental retardation has been identified in infants of mothers treated with phenytoin and has been called the 'fetal hydantoin syndrome'. ${ }^{7}$ Though exposure to anticonvulsant drugs has been suggested as a cause of these anomalies ${ }^{39}$ some of them may be genetically linked to epilepsy. ${ }^{4} 10$

Various neonatal conditions have been described in infants born to epileptic mothers, including irritability, ${ }^{211}$ gingival hyperplasia, ${ }^{2}$ and haemorrhage as a result of a coagulation defect. ${ }^{12}$ The irritability may have been a symptom of withdrawal of the drug at birth. ${ }^{13}$

In the present study the incidence of congeni- tal anomalies and neonatal conditions in infants born to epileptic mothers were compared with those in a control group born to mothers without epilepsy. Hypoplasia of the finger and toenails and jitteriness, which were commonly seen in infants of epileptic mothers, were related to phenytoin concentrations in maternal blood and cord blood, respectively. Infants of epileptic mothers and of controls were followed up at outpatient clinics.

\section{Patients and methods}

MOTHERS

A group of pregnant mothers each of whom gave a history of grand mal epilepsy and who were referred to our antenatal clinic from $1 \mathrm{Sep}$ tember 1980 to 31 August 1982 were included in the study. They attended a special clinic every two weeks for routine hospital antenatal care, clinical assessment of seizure control, and adjustment of anticonvulsant dosage in accordance with serum drug concentration or clinical response. Control mothers were selected at the time of antenatal booking and were matched for maternal age, parity, and social class. There were no heavy smokers (defined as smoking more than 20 cigarettes/day), none had medical complications such as diabetes or hypertension, and none of the control mothers were taking any drugs regularly. Folic acid ( $15 \mathrm{mg} /$ day) was prescribed for all mothers. The groups were comparable (table 1).

\section{ANTICONVULSANT DRUGS}

Maternal serum drug concentrations were maintained within therapeutic ranges for phenytoin

Table 1 Infants born to epileptic mothers and controls

\begin{tabular}{|c|c|c|}
\hline & $\begin{array}{l}\text { Infants of } \\
\text { epileptic } \\
\text { mothers } \\
(n=61)\end{array}$ & $\begin{array}{l}\text { Controls } \\
(n=62)\end{array}$ \\
\hline $\begin{array}{l}\text { Mean (SD) maternal age (years) } \\
\text { Mode of delivery: }\end{array}$ & $26.5(4.9)$ & $26 \cdot 6(4 \cdot 8)$ \\
\hline $\begin{array}{l}\text { Spontaneous vaginal } \\
\text { Forceps } \\
\text { Caesarean section }\end{array}$ & $\begin{array}{r}37 \\
5 \\
19\end{array}$ & $\begin{array}{l}40 \\
10 \\
12\end{array}$ \\
\hline $\begin{array}{l}\text { Gestational age (weeks): } \\
\text { Preterm (28-36) } \\
\text { Full term }(37-42)\end{array}$ & $\begin{array}{r}8 \\
53\end{array}$ & $\begin{array}{r}3 \\
59\end{array}$ \\
\hline $\begin{array}{l}\text { Birth weight }(\mathrm{g}): \\
1080-2499 \\
2500-4600 \\
\text { Small for dates }\end{array}$ & $\begin{array}{r}8 \\
53 \\
2\end{array}$ & $\begin{array}{r}3 \\
59 \\
2\end{array}$ \\
\hline $\begin{array}{l}\text { Occipitofrontal head circumference }(\mathrm{cm}) \\
28 \cdot 0-32 \cdot 9 \\
33 \cdot 01-35 \cdot 9 \\
36 \cdot 0-39 \cdot 9 \\
\text { Congenital anomalies: } \\
\text { Neonatal complications }\end{array}$ & $\begin{array}{l}14 \\
36 \\
11 \\
26^{* *} \\
26^{* *}\end{array}$ & $\begin{array}{r}7 \\
38 \\
17 \\
0 \\
6\end{array}$ \\
\hline
\end{tabular}

${ }^{* *} \mathrm{p}<0 \cdot 001$, Fisher's exact test.

St Mary's Hospital,
Hathersage Road,
Manchester M13 OJH,
Department of
Child Health
S W D'Souza
Department of Obstetrics
I G Robertson
Department of Genetics
D Donnai
Department of
Physiological Sciences,
University of Manchester
G Mawer
Correspondence to:
Dr D'Souza.
Accepted 18 September 1990


Table 2 Congenital anomalies among 61 infants of epileptic mothers

\begin{tabular}{|c|c|c|c|c|c|c|c|c|c|c|c|c|}
\hline & \multicolumn{5}{|c|}{ Single drug throughout pregnancy } & \multicolumn{3}{|c|}{ Drugs only in first trimester } & \multirow{2}{*}{$\begin{array}{l}\text { Combin- } \\
\text { ations of } \\
\text { drugst }\end{array}$} & \multirow{2}{*}{$\begin{array}{l}\text { No } \\
\text { drugs }\end{array}$} & \multirow[t]{2}{*}{ Total } & \multirow[t]{2}{*}{ Controls } \\
\hline & Phenytoin & Carbemazepine & Phenobarbitone & Valproate & Clonazepam & Phenytoin & Phenobarbitone & e Valproate & & & & \\
\hline $\begin{array}{l}\text { No of infants } \\
\text { Total No with congenital }\end{array}$ & 22 & 3 & 4 & 1 & 1 & 1 & 2 & 1 & 18 & 8 & 61 & 62 \\
\hline anomalies: & 12 & 2 & 1 & $\mathbf{0}$ & $\mathbf{0}$ & $\mathbf{0}$ & $\mathbf{0}$ & $\mathbf{0}$ & 10 & 1 & $26^{* *}$ & 0 \\
\hline Cranial nerve palsy & - & 1 & 1 & - & - & - & - & - & - & - & 2 & - \\
\hline Epicanthic folds & 1 & - & - & - & - & - & - & - & 2 & - & 3 & - \\
\hline $\begin{array}{l}\text { Extra digits } \\
\text { Flattened bridge of nose }\end{array}$ & 1 & 1 & - & - & - & - & - & - & - & - & 2 & - \\
\hline and hypertelorism & - & - & - & - & - & - & - & - & 1 & - & 1 & - \\
\hline Heart disease & 1 & - & 1 & - & - & - & - & - & 2 & 1 & 5 & - \\
\hline Dislocation of hip & 1 & - & - & - & - & - & - & - & - & - & 1 & - \\
\hline Hypoplastic nails & 5 & - & - & - & - & - & - & - & 6 & - & $11^{*}$ & 一 \\
\hline Distal phalangeal hypoplasia & 1 & - & - & - & - & - & - & - & 2 & - & 3 & - \\
\hline Hypospadias & 1 & - & - & - & - & - & - & - & - & - & 1 & - \\
\hline Inguinal hernia & - & - & - & - & - & - & - & - & 1 & - & 1 & - \\
\hline $\begin{array}{l}\text { Ptosis } \\
\text { Craniosynostosis (saggital }\end{array}$ & 1 & - & - & - & - & - & - & - & - & - & 1 & - \\
\hline suture) & 2 & - & - & - & - & - & - & - & - & - & 2 & - \\
\hline Transverse palmar crease & - & - & - & - & - & - & - & - & 2 & - & 2 & - \\
\hline Down's syndrome & 1 & - & - & - & - & - & - & - & - & - & 1 & - \\
\hline
\end{tabular}

(10-25 mg/l), ${ }^{14}$ carbamazepine (4-10 mg/l), ${ }^{15}$ and phenobarbitone $(10-40 \mathrm{mg} / \mathrm{l})^{15} 16$ by adjustment of dosage. In early pregnancy (gestational age less than 20 weeks) we tried to keep the serum drug concentration in the low to middle part of the therapeutic range but in later pregnancy (to offset an expected rise in the frequency of seizures) the doses were increased to achieve concentrations in the middle to upper part of the therapeutic range. Serum drug concentrations were determined by high performance liquid chromatography (HPLC) by the methods of Adams and Vandemark, ${ }^{17}$ and Kabra et $a l .{ }^{18}$ In the relatively small number of mothers who were taking valproate, sulthiame, or clonazepam (table 2) serum drug concentrations were not routinely measured. The dose of the drug was adjusted as recommended in the British National Formulary to achieve control of seizures. ${ }^{19}$ If the control deteriorated, the mother was admitted to hospital for neurological investigations and stabilisation. Such mothers sometimes required additional loading doses of anticonvulsant drugs.

INFANTS

Each infant's condition at birth was assessed by a subset of the Apgar scoring method. ${ }^{20} \mathrm{~A}$ segment of umbilical cord was clamped and venous blood was collected for serum phenytoin estimation. Birth weights were measured by a beam balance. The occipitofrontal head circumference was measured with a paper measuring tape. Gestational age, calculated from the first day of the last menstrual period, was checked by assessment of various neurological and external characteristics in each newborn infant. ${ }^{21}$ Each infant was examined by a paediatrician (SWD'S) and a geneticist (DD), neither of whom was aware of whether the mother was in the study group or the control group. Infants were deemed 'small for dates' if their birth weights were less than the third centile for gestational age. ${ }^{22}$ In later childhood the children were assessed for developmental delay (developmental quotient less than 70) using Griffiths's mental developmental scales when they were between 2.5 and 3.5 years old. ${ }^{23}$ Information was obtained from parents and, where possible, school teachers about learning difficulties at school between 1986 and 1989 .

\section{STATISTICAL ANALYSIS}

The data were analysed with Student's $t$ test, Fisher's exact test, or the $\chi^{2}$ test. A probability of $<0.05$ was accepted as significant.

\section{Results}

With one exception the infants born to mothers with epilepsy (study group) and the controls were in a good condition at birth, ${ }^{20}$ and required only routine care. The one exception was an infant who was born to a mother who had an epileptic fit during labour; this infant gasped at birth and after oxygen was administered by face mask regular respirations were established within a five minute period. Mean maternal age and details of the infants are shown in table 1 . The proportions of preterm infants in both groups were statistically similar. In the study group, three preterm infants had gestational ages of 28 to 32 weeks, and the remaining five infants had gestational ages of 33 to 36 weeks. In the control group, the gestational ages of the three preterm infants were 33 to 36 weeks. More infants in the study group had congenital anomalies or neonatal conditions compared with controls.

\section{CONGENITAL ANOMALIES}

Twenty six of 61 infants (43\%) had congenital anomalies in the study group compared with none of 62 control infants (table 2). These anomalies occurred in 15 of 31 infants $(48 \%)$ whose mothers had treatment with a single drug throughout pregnancy, 10 of 18 infants $(56 \%)$ whose mothers had a mixture of drugs and one (13\%) of eight infants whose mothers had a history of epilepsy but received no drugs during pregnancy; none of the four infants whose mothers had had treatment with a single drug during the first trimester only were affected. 
Table 3 Incidence of hypoplastic nails in infants with congenital anomalies born to mothers with epilepsy

\begin{tabular}{|c|c|c|c|}
\hline & \multicolumn{2}{|c|}{ No with congenital anomalies } & \multirow{2}{*}{$\begin{array}{l}\text { No with no } \\
\text { congenital } \\
\text { anomalies }\end{array}$} \\
\hline & Total No & $\begin{array}{l}\text { No with } \\
\text { hypoplastic nails }\end{array}$ & \\
\hline $\begin{array}{l}\text { Mothers taking no drugs }(n=8) \\
\text { Mothers taking phenytoin alone or in combination }(n=36) \\
\text { Mothers taking drugs other than phenytoin }(n=17)\end{array}$ & $\begin{array}{r}1 \\
21 \\
4\end{array}$ & $\begin{array}{r}0 \\
11 \\
0\end{array}$ & $\begin{array}{r}7 \\
15 \\
13\end{array}$ \\
\hline Total $(n=61)$ & 26 & 11 & 35 \\
\hline
\end{tabular}

Table 4 Mean (SD) maternal serum phenytoin concentrations $(\mathrm{mg} / \mathrm{l})$ in the second and third trimesters of pregnancy

\begin{tabular}{|c|c|c|c|}
\hline & $\begin{array}{l}\text { Infants with } \\
\text { hypoplastic } \\
\text { nails } \\
(n=11)\end{array}$ & $\begin{array}{l}\text { Infants with } \\
\text { normal nails } \\
(n=24)\end{array}$ & $\stackrel{p}{\text { Value* }}$ \\
\hline $\begin{array}{l}\text { Second trimester } \\
\text { Third trimester } \\
\text { Second and third trimesters }\end{array}$ & $\begin{array}{l}15 \cdot 9(6 \cdot 0) \\
20 \cdot 5(6 \cdot 9) \\
18 \cdot 2(5 \cdot 8)\end{array}$ & $\begin{array}{l}10 \cdot 9(4 \cdot 5) \\
15.6(6 \cdot 3) \\
13.3(5 \cdot 0)\end{array}$ & $\begin{array}{l}<0.05 \\
<0.05 \\
<0.05\end{array}$ \\
\hline
\end{tabular}

Most of the infants had minor congenital abnormalities (table 2), though there were some children with major defects. One infant born to a 29 year old mother who had phenytoin throughout pregnancy had Down's syndrome. Five infants had congenital heart disease in the form of atrial septal defect $(n=2)$, ventricular septal defect $(n=1)$, patent ductus arteriosus $(n=1)$, and hypoplastic left heart syndrome $(n=1)$. Two infants had cranial nerve palsy. One infant with a right facial palsy and hypoglossal nerve palsy had been exposed to carbamazepine throughout pregnancy and was born by caesarean section. The other infant with bilateral abducent nerve palsy (associated with a patent ductus arteriosus) was born to a mother who had been taking phenobarbitone throughout pregnancy.

Hypoplasia of nails was more common than any other congenital anomaly (table 2), 11 infants (18\%) being affected. Hypoplastic nails were recorded if several finger or toenails were small, brittle, and deeply set with an irregular surface and yellow discoloration. Hypoplasia of the fifth toenail, which is a common finding among newborn babies, was not recorded. All the infants with hypoplastic nails had been exposed to phenytoin in the uterus (in five it was the only drug and in six it was in combination with other anticonvulsant drugs). Infants born to epileptic mothers who were taking anticonvulsant drugs other than phenytoin, or those born to similar mothers who had not received anticonvulsant drugs, did not have hypoplastic nails (table 3). Some infants had hypoplastic nails alone, while others had hypoplastic nails in combination with other congenital anomalies including distal phalangeal hypoplasia, flattened bridge of the nose and hypertelorism, congenital heart disease, inguinal hernia, and transverse palmar crease. Table 4 shows the mean maternal serum phenytoin concentrations in infants wth hypoplastic nails compared with those in infants with normal nails. The differences in maternal phenytoin concentrations were significant in the second and third trimesters of pregnancy. Hypoplastic nails were associated with increased maternal phenytoin concentrations.

\section{NEONATAL CONDITIONS}

Neonatal conditions were diagnosed in 26 of 61 infants in the study group (43\%) and six of 62 controls (10\%) (table 5). 'Jitteriness' was common, being recorded in 11 infants in the study group $(18 \%)$ but not among controls. Such infants seemed excitable with increased muscle tone and reflexes, tremors, and a heightened Moro reflex. ${ }^{24}$ The jittery infants were born to mothers who had: phenytoin alone $(n=2)$; valproate alone $(n=1)$; a combination of drugs including carbamazepine, phenytoin, phenobarbitone, valproate, sulthiame, and primidone $(n=7)$; and no drugs $(n=1)$ during pregnancy.

Table 5 Neonatal conditions

\begin{tabular}{|c|c|c|c|c|c|c|c|c|c|c|c|c|}
\hline & \multicolumn{5}{|c|}{ Single drug throughout pregnancy } & \multicolumn{3}{|c|}{ Drugs only in first trimester } & \multirow{2}{*}{$\begin{array}{l}\text { Combin- } \\
\text { ations of } \\
\text { drugst }\end{array}$} & \multirow{2}{*}{$\begin{array}{l}\text { No } \\
\text { drugs }\end{array}$} & \multirow[t]{2}{*}{ Total } & \multirow{2}{*}{$\begin{array}{l}\text { Controls } \\
(n=62)\end{array}$} \\
\hline & Phenytoin & Carbemazepine & Phenobarbitone & Valproate & Clonazepam & Phenytoin & Phenobarbitone & Valproate & & & & \\
\hline No of infants & 22 & 3 & 4 & 1 & 1 & 1 & 2 & 1 & 18 & 8 & 61 & 62 \\
\hline $\begin{array}{l}\text { Total No with neonatal } \\
\text { conditions }\end{array}$ & 11 & 1 & 0 & 1 & 0 & 0 & 0 & 0 & 11 & 2 & $26 * *$ & 6 \\
\hline Cephalhaematoma & 11 & 1 & - & 1 & - & - & - & - & 11 & - & 1 & 2 \\
\hline Conjunctivitis & 2 & - & - & - & - & - & - & - & - & - & 2 & - \\
\hline $\begin{array}{l}\text { Pustular rash } \\
\text { Feeding difficulty (tube }\end{array}$ & 1 & - & - & - & - & - & - & - & 1 & - & 2 & 2 \\
\hline fed) & - & - & - & - & - & - & - & - & 2 & - & 2 & - \\
\hline Fits (hypocalcaemia) & - & - & - & - & - & - & - & - & $i$ & - & 1 & - \\
\hline $\begin{array}{l}\text { Floppy (hypotonia) } \\
\text { Periventricular haemorrhage }\end{array}$ & 2 & - & - & - & - & - & - & - & - & - & 2 & - \\
\hline $\begin{array}{l}\text { Periventncular haemorrhage } \\
\text { (germinal layer) }\end{array}$ & 1 & - & - & - & - & - & - & - & - & - & 1 & - \\
\hline Jaundice & 2 & 1 & - & - & - & - & - & - & 1 & 1 & 5 & 2 \\
\hline Jittery & 2 & - & - & 1 & - & - & - & - & 7 & 1 & $11^{*}$ & - \\
\hline $\begin{array}{l}\text { Apnoeic episodes } \\
\text { Idiopathic respiratory }\end{array}$ & - & - & - & - & - & - & - & - & 1 & - & 1 & - \\
\hline distress & 1 & - & - & - & - & - & - & - & 1 & - & 2 & - \\
\hline Sepsis & 1 & - & - & - & - & - & - & - & 1 & - & 2 & - \\
\hline Transient tachypnoea & - & - & - & - & - & - & - & - & l & - & 1 & - \\
\hline
\end{tabular}

${ }^{*} \mathrm{p}<0.05,{ }^{* *} \mathrm{p}<0.001$, Fisher's exact test.

tCombinations included phenytoin, carbamazepine, phenobarbitone, primidone, valproate, clonazepam, and sulthiame.

0 , No infants with neonatal conditions.

-, Absence of a particular neonatal condition. 
Among those mothers who had taken phenytoin (alone or in combination with other drugs) there was no significant difference in the mean (SD) cord blood serum phenytoin concentrations between infants with jitteriness $(16.3(7 \cdot 0) \mathrm{mg} / \mathrm{l}$, $\mathrm{n}=11)$ and those without jitteriness $(15 \cdot 7(7 \cdot 8)$ $\mathrm{mg} / \mathrm{l}, \mathrm{n}=25$ ). All the jittery infants were in a good condition at birth and none had had birth asphyxia. One jittery infant developed tonic and clonic seizures on day 2 as a result of hypocalcaemia (serum calcium concentration 0.9 $\mathrm{mmol} / \mathrm{l}$ ).

There were two neonatal deaths (at 21 hours and 28 hours of age) among infants of mothers with epilepsy. The first infant was born preterm at 32 weeks' gestational age and had idiopathic respiratory distress and pneumothorax. The second infant was born at a similar gestational age and had intrauterine growth retardation and congestive heart failure caused by a hypoplastic left heart.

\section{FOLLOW UP}

Among infants with hypoplastic nails at birth, improved nail growth had taken place by 3 months of age. The jitteriness that was observed during the first three days of birth had resolved by 2 weeks. Excluding the child with Down's syndrome, none of the remaining children in the study group had a major impairment in later childhood. There were therefore no children with neuromotor impairment caused by cerebral palsy and none with sensorineural hearing loss, impaired vision, epilepsy, or developmental delay. The median (range) developmental quotients of the children of epileptic mothers (excluding the child with Down's syndrome) and of controls were 94 (75-134) and 98 (90120), respectively. With the exception of the child with Down's syndrome (who attended a special school) the children in both groups attended normal schools. One child in the study group received special help at school for serious learning difficulties; he also had some dysmorphic features including a flattened bridge of the nose and hypertelorism. ${ }^{25}$ These findings were associated with severe reading and spelling difficulty, impaired language development, and visuospatial defects.

\section{Discussion}

The high incidence of congenital anomalies in the present study $(43 \%)$ is nearly four times that mentioned in a review of previous prospective studies of infants born to epileptic mothers. ${ }^{6}$ This unexpected result may be the result of differences in the methods of assessment and reporting of congenital anomalies. Alternatively, the differences might have arisen because of the way we managed anticonvulsant drugs during pregnancy; doses were increased as gestational age advanced to maintain serum concentrations of phenytoin, phenobarbitone, and carbamazepine within a 'therapeutic range' and to reduce the risk of epileptic fits during pregnancy. This could, however, have influenced fetal growth and development only in the second and third trimesters of pregnancy.
Because organogenesis during the first trimester would not have been affected we had expected the incidence of congenital anomalies to be similar to that previously reported. It has been suggested that folate supplements may have a protective effect if the teratogenic effect of anticonvulsants is caused by folate antagonism. ${ }^{5}$ In our study it is doubtful whether giving such supplements was of any benefit, either because folic acid was prescribed too late or because the congenital abnormalities were not mediated by folate antagonism.

Most of the congenital anomalies we observed are common among infants of epileptic mothers. Nevertheless, there are certain differences between this and other studies. Firstly, hypoplastic nails were more common than any other congenital anomaly in our study, while previous studies have reported medial epicanthic folds, a large anterior and posterior fontanelle, or a broad nasal bridge as being more common in such infants. ${ }^{24}$ Secondly, there were no cases of orofacial clefts in the present study. In contrast, a similar anomaly had increased roughly tenfold in infants of epileptic mothers. ${ }^{26}$ Thirdly, cranial nerve anomalieswhich were found in two (3\%) of our infants of epileptic mothers-have not previously been reported. The present findings have raised the possibility of agenesis of the cranial nerve nuclei as a result of fetal exposure to carbamazepine or phenobarbitone. ${ }^{27}$ Fourthly, one infant with Down's syndrome was born to a 29 year old mother in the study group. At this maternal age the incidence of liveborn infants with Down's syndrome is about 1:935 but it is not known whether the incidence is affected by maternal epilepsy or anticonvulsant treatment. ${ }^{28}$

In the present study hypoplastic nails resulting from treatment with phenytoin in pregnancy were associated with higher mean maternal phenytoin concentrations in the second and third trimesters. It appeared that hypoplasia of the nails was dependent on differences in maternal serum phenytoin concentrations within the range $10-25 \mathrm{mg} / 1 .^{14}$ It is not clear why phenytoin should affect nails particularly, and not all the other ectodermal structures in these infants. In contrast Gaily et al reported hypoplastic nails among infants of epileptic mothers who had been on other anticonvulsant drugs (excluding phenytoin) as well as among infants of epileptic mothers who had not taken drugs during pregnancy. ${ }^{4}$ It would seem, therefore, that there may be an appreciable genetic influence that contributes to the development of hypoplastic nails in addition to the effect of phenytoin. The possibility of interactions between genetic factors and drugs may mean that anticonvulsant drugs have teratogenic effects in some infants but not in others. ${ }^{3}$

Neonatal jitteriness may result from withdrawal of the drug. ${ }^{13}$ It was observed in our infants within a three day period of birth, and did not seem to be related to a specific drug or to cord serum phenytoin concentrations. In addition, our study has shown that jitteriness occurred in one of eight infants born to epileptic mothers who did not receive drugs during pregnancy. This raises the possibility that there are other 
causes of jitteriness including a reduced calcium concentration such as occurred in one infant who developed tonic and clonic seizures.

Although an increased incidence of various congenital anomalies and neonatal conditions was observed in the infants born to epileptic mothers, those infants who survived seemed to do so without major impairments though one of them had a serious learning disability. We are aware that Gaily et al have recently reported that in spite of equal general intelligence the children of epileptic mothers had impaired visuospatial, auditory and speaking skills compared with children of non-epileptic mothers. ${ }^{29}$ In addition, these authors suggested that children of epileptic mothers have an increased risk of specific cognitive dysfunction that contributes to learning difficulty.

Our study raises the possibility that maintaining maternal drug concentrations within a 'therapeutic' range may have benefited the infants in preventing some serious congenital malformations; there were none with orofacial clefts. Unfortunately maternal drug concentrations were not monitored near the time of conception or in the first few days after conception. From the information we have about maternal drug concentrations it is not possible to draw any conclusions about the relative risks of congenital abnormalities with different anticonvulsant drugs. Monitoring maternal serum anticonvulsant concentrations did not prevent neonatal deaths. Hypoplastic nails and jitteriness in these infants did not seem to have any serious long term effects.

We thank the North Western Regional Health Authority for financial support; the clinical psychologists, school teachers, clinical medical officers, and general practitioners who helped with our study; Dr ML Chiswick and Dr DG Sims for allowing us our study; Dr ML Chiswick and Dr DG Sims for allowing us
access to preterm infants in the special care baby unit; Professor RDH Boyd for reviewing the manuscript and providing useful comments; and Mrs Elaine Evans for secretarial assistance.

1 Meadow SR. Anticonvulsant drugs and congenital abnormalities. Lancet 1968;ii:1296.

2 ties. Lancet 1968;ï: 1296 . NF, Houston RN. Infants exposed in utero to antiepileptic drugs. Am $\mathcal{I}$ Dis Child 1974;127:645-53.

3 Anonymous. Teratogenic risks of antiepileptic drugs. $B M \mathcal{Y}$ 1981;283:515-6.

4 Gaily E, Granstrom M-L, Hulesmaa V, Baray A. Minor anomalies

Meadow SR. Maternal epilepsy and abnormalities of the fetus and newborn. Lancet 1972;ii:839-43.

$6 \mathrm{Janz}$ D. On major malformations and minor anomalies in the offspring of parents with epilepsy. In: Janz D, Dam $M$, offspring of parents with epilepsy. In: Janz D, Dam M,
Richens A, Boosi L, Helge HG, Schmidt D, eds. Epilepsy, pregnancy and the child. New York: Raven Press, 1982 : pregnancy

7 Hanson JW, Smith DW. The fetal hydantoin syndrome. f Pediatr 1975;87:285-90.

8 Janz D. The teratogenic risk of antiepileptic drugs. Epilepsia 1975;16:159-69.

9 Kelly TE, Edwards P, Rein M, Miller JO, Dreifuss FE. Teratogenicity of anticonvulsant drugs. 11. A prospective study. Am F Med Genet 1984;19:435-43.

10 Van Dyke DC, Hodge SE, Heide F, Hill LR. Family studies in fetal hydantoin exposure. I Pediatr 1988;113:301-6.

11 Desmond MM, Schwanecke RP, Wilson GS, Yasunga S Burgdorff I. Maternal barbiturate utilization and neonata withdrawal symptomatology. I Pediatr 1972;80:190-7.

12 Mountain KR, Hirsh J, Gallus AS. Neonatal coagulation defect due to anticonvulsant drug treatment in pregnancy. defect due to anticon
Lancet $1970 ; \mathrm{i}: 265-8$.

13 Erith MJ. Withdrawal symptoms in newborn infants of epileptic mothers. $B M \mathcal{F}$ 1975; iii:30.

14 Richens A, Dunlop A. Serum phenytoin levels in management of epilepsy. Lancet 1975;ii:247-8.

15 Reynolds EH. How do anticonvulsants work? Br $\mathcal{F}$ Hosp Med 1978;5:505-12.

16 Eadie MJ. Which anticonvulsant drug? Drugs 1979;17:213-8 7 Adams RF, Vandemark FL. Simultaneous high-pressure liquid chromatographic determination of some anticonvulsants in serum. Clin Chem 1976;22:25-31.

18 Kabra PM, Stafford BE, Marton LJ. Simultaneous measurement of phenobarbital, phenytoin, primidone, ethosux mide and carbamazepine in serum by high pressure, liquid chromatography. Clin Chem 1977;23:1284-8.

19 British Medical Association and Royal Pharmaceutical Society of Great Britain. British national formulary. London: BMA and Royal Pharmaceutical Society of Great Britain, 1980, No 1 .

20 D'Souza SW, John RW, Richards B, Milner RDG. Fetal distress and birth scores in newborn infants. Arch Dis Child tress and birth

21 Dubowitz LMS, Dubowitz V, Goldberg C. Clinical assessment of gestational age in the newborn. $\mathcal{F}$ Pediatr 1970;77. $1-10$

22 Keen DV, Pearse RG. Birthweight between 14 and 42 weeks gestation. Arch Dis Child 1985;60:44-6.

23 Griffiths R. The abilities of babies: a study of mental measurement. Amersham: Association for Research in Infants and Child Development, 1976

24 D'Souza SW, Richards B. Neurological sequelae in newborn babies after perinatal asphyxia. Arch Dis Child 1978;53: $564-9$.

25 Smith DW. Recognizable patterns of human malformations. 3rd Ed. Philadelphia: WB Saunders, 1982

26 Meadow SR. Congenital malformations and seizure disorders in offspring of parents with epilepsy. Dev Med Child Neurol 1979;21:536-8.

27 Robertson I, Donnai D, D'Souza S. Cranial nerve agenesis in a fetus exposed to carbamazepine. Dev Med Child Neurol 1983;25:540-1.

28 Hooke EB, Chambers GM. Estimated rates of Down syndrome in live births by one year maternal age intervals for drome in live births by one year maternal age intervals for
mothers aged $20-49$ in a New York state study. Birth mothers aged 20-49.

29 Gaily E, Kantola-Sorsa E, Granstrom M-L. Specific cognitive dysfunction in children with epileptic mothers. Dev Med Child Neurol 1990;32:403-14. 